\title{
DECALCOMANIA, MAPPING AND MIMESIS
}

\section{ZAFER ARACAGÖK}

In the second place, singularities possess a process of auto unification, always mobile and displaced to the extent that a paradoxical element traverses the series and makes them resonate....

-Gilles Deleuze ${ }^{1}$

\section{Zero: Resonance}

What if these two terms, 'decalcomania' and 'mapping' are already in resonance before a decision separates them as such? Not only because Deleuze refers here and there to 'resonance,' but also, and mainly, because of the lure of the word, or an invitation by Nietzsche to a resonance that destroys, disturbs, and produces noise when it comes to questions like the immediate and the event in Deleuze? And what if this paradoxical element is nothing more than 'mimesis' itself?

Therefore, 'resonance' in different senses of the word:

1) Physics and Chem. (i) Generally, a condition in which a particle is subjected to an oscillating influence (as an electromagnetic field or another particle) of such a frequency that a transfer of energy occurs or reaches a maximum.

2) Mech. (i) A condition in which an object or system is subjected to an oscillating force having a frequency close to that of a natural vibration of the object or system; the resulting amplification of the natural vibration.

3) Electr. The phenomenon of an oscillating signal (as an electric current or electromagnetic radiation) producing an effect upon an oscillating current of the same frequency; the condition in which a circuit or device produces the largest

${ }^{1}$ Deleuze $(2003,103)$. 
possible response to an applied oscillating signal, esp. when its inductive reactance balances its capacitative reactance. ${ }^{2}$

Definition of resonance, as one can follow in the entries above was modeled, at least initially, on a relationship between a source and another object on which this source acts upon, say, as in a relationship between a model and a copy: obviously a definition which is heavily predetermined with positing the source as the origin of resonance. However, with the unfolding of the quantum theory, ${ }^{3}$ there arises, in contrast, a second definition which replaces the first definition by distributing the privilege of being the source or the origin of resonance among all the objects, thereby eliminating the question of the source from its privileged position. One also observes in the second definition that each object, without the necessity of an originator, is always already in vibration, and resonance is what happens between those vibrating multiplicity of 'sources.'

Deleuze refers to a concept of resonance, especially in The Logic of Sense (2003), whenever it is a matter of defining a relationship between 'two series,' or, developing a strategy against the return of the Hegelian dialectics so that any moment of 'aufhebung' is avoided. One question to be raised here is whether the distribution of this concept of 'resonance' in the philosophy of Deleuze functions as it is supposed to function. And, if so, does he want us to presume that it is this second definition of resonance that he has in mind whenever he refers to this term in order to explain, say, the relationship between model and copy in a simulacrum, ${ }^{5}$ between singularities, ${ }^{6}$ between chaos and the image of thought, between bodies and events, between actual and virtual, etc?

2All entries on "resonance" are from OED online.

3I am indebted to Arkady Plotnitsky and his work on the development of quantum theory, and the detailed account he gives of the debate between Einstein-Schrödinger and Bohr-Heisenberg (see for example, Plotnitsky, The Knowable and the Unknowable: Modern Science, Nonclassical Thought, and the Two Cultures [2002] and Complementarity: AntiEpistemology After Bohr and Derrida [1994]) which throws light on the question of resonance that I elaborate upon in my book project on Deleuze.

"The word, "to resonate," first appears in The Logic of Sense on page 56 as follows: ". . how are we to characterize the paradoxical element which runs through the series, makes them resonate, communicate, and branch out, and which exercises command over all repetitions, transformations and redistributions?" Later again on pages 66, 179, 226, 228, $232,239,261,283$, Deleuze refers to "resonance" as the principle of the relationship between 'two series.'

5See, for example, Appendix 1 "The Simulacrum and Ancient Philosophy" in The Logic of Sense, where Deleuze uses a term, 'internal resonance' in order to explain the relationship between series (261). "Between these basic series, a sort of internal resonance is produced, and this resonance induces a forced movement." He does not give a reference to it, but we know that "internal resonance" is a term which he borrows from Gilbert Simondon's L'individu et sa genese physico-biologique (1964). For a short but illuminating introduction to Simondon, see Deleuze's "On Gilbert Simondon" in Desert Islands and Other Texts, 1953-1974 (2004).

"See especially the "Conclusion" of Deleuze's Difference and Repetition (2001) where Deleuze discuses the relationship between Ideas and singularities: "A singularity is the 
Despite all the nuances included in the concept of resonance in Deleuze, I will initially offer in this article that the question of resonance is closely related to the question of 'the first' in Deleuze's philosophy. 'Decalcomania' and 'mapping' in this sense are only two areas of my investigation of the question of "the first" by means of which I will foreground the problematic position of mimesis in Deleuze. And the question of mimesis will be taken into consideration later in relation to 'simulacra,' 'actualisation/counter-actualisation,' 'Dionysian machine' and, 'the image of thought' with the intention of raising the following question: Is there something else which puts the Deleuzian 'resonance' into resonance?

\section{One}

Bearing in mind this question of resonance, let us concentrate for a while on the problematique relationship between 'decalcomania' and 'mapping' which Deleuze and Guattari develop in the introduction to $A$ Thousand Plateaus (1987). As we all know this is where they are formulating the concept of rhizome, and as they proceed to the "principle 5 and 6," they introduce an opposition between cartography and decalcomania, out of which they reach the following conclusion:

The rhizome is altogether different, a map and not a tracing. Make a map, not a tracing. The orchid does not reproduce the tracing of the wasp; it forms a map with the wasp, in a rhizome. What distinguishes the map from tracing is that it is entirely oriented toward an experimentation in contact with the real. The map does not reproduce an unconscious closed in upon itself; it constructs the unconscious. (12)

In this paragraph and also in the rest of the introduction, as they move along, they develop a concept of rhizome where the relationship between a model and copy gets lost with a preference of a world of maps getting connected to each other in multiple, indeterminable ways. In their view, mapping "fosters connections between fields, the removal of blockages on bodies without organs, the maximun opening of bodies without organs onto a plane of consistency. It is itself a part of the rhizome. The map is open and connectable in all of its dimensions; it is detachable, reversible, susceptible to constant modification. It can be torn, reversed, adapted to any kind of mounting, reworked by an

point of departure for a series which extends over all the ordinary points of the system, as far as the region of another singularity which itself gives rise to another series which may either converge with or diverge from the first. Ideas have the power to affirm divergence; they establish a kind of resonance between divergent series" (278). 
individual, group or social formation. It can be drawn on a wall, conceived of as a work of art, constructed as a political action or as a meditation" (12).

However, one paragraph later, realising that they have given way to a new binarism, they give an explanation as follows: "Have we not, however, reverted to a simple dualism by contrasting maps to tracings, as good and bad sides? Is it not of the essence of the map to be traceable? Is it not of the essence of the rhizome to intersect roots and sometimes merge with them?" (13). And, in the next paragraph we learn something new about their method: the way their theory leads to binarisms or dualisms is explained by referring to a "reverse but nonsymmetrical" operation (14). In other words, when tracing is opposed to mapping it is not because these two constitute an absolute opposition or binarism but because they constitute a pair where although one of the two seems to be the opposite of the other, it is only a nonsymmetrical reversal of the other. "Thus, there are very diverse map-tracings, rhizome-root assemblages, with variable coefficients of deterritorialisation. There exist tree or root structures in rhizomes; conversely, a tree branch or root division may begin to burgeon into a rhizome. The coordinates are determined not by theoretical analyses implying universals but by a pragmatics composing multiplicities or aggregates of intensities. A new rhizome may form in the heart of a tree, the hollow of a root, the crook of a branch." (15)

To a certain extent, this operation can be related to Deleuze and Guattari's method - as Deleuze himself put it at different times and also in different contexts - to the importance they give to the creation of concepts, which in their view is the duty of the philosopher. And, as we know from different contexts, the creation of concepts in Deleuze and Guattari does not take the form of rigid, fixed concepts. Rather, it is an act of transformations, or becomings so that a concept never remains as it is. Their text demands a reading based on construction and destruction at the same time such that a concept as such never comes into being. When they, for example, write that "a book is not the image of the world," it is directly related to its opposite: "a book is also an image of the world," for as they describe in "Rhizome," tracing is what carries the possibility of being transformed into mapping which should be seen as Deleuze and Guattari's way of dealing with binary oppositions. In other words, if oppositions are in opposition it only means that they are different but inseperable entities ${ }^{7}$ for everything happens in a plane of immanence.

As they put it:

\footnotetext{
7For this issue, see especially Deleuze's The Fold: Leibniz and the Baroque (1993).
} 
The same applies to the book and the world: contrary to a deeply rooted belief, the book is not an image of the world. It forms a rhizome with the world, there is an aparallel evolution of the book and the world; the book assures the deterritorialisation of the world, but the world effects a reterritorialisation of the book, which in turn deterritorialises itself in the world (if it is capable, if it can). Mimicry is a very bad concept, since it relies on binary logic to describe phenomena of an entirely different nature. (11)

Now, as Deleuze and Guattari stress, this claim, "the book is not the image of the world," can be asserted only with respect to "a deeply rooted belief," which is "the book is the image of the world." And, apparently, for them, mimicry is that which is responsible for all such binarisms, and that which has to be eliminated from thought.

I would like to propose at this point that here, and also in similar cases, one comes face to face with a certain mode of thinking which has the elimination of mimicry (all that pertains to models, copies and representation) as its project, and which, probably because of this insistence on 'elimination,' continuously yields to contradictions. The contradiction I am talking about is not that which presents itself as a case of $A=A$, and it cannot be $A^{\prime}$ for as we all know Deleuze, especially in Difference and Repetition (2001a) rejects the category of contradiction on the ground that it belongs to the principle of identity (268).

The contradiction that I want to foreground is quite related to the way in which the binaries are preserved within rhizome within an 'and ... and . . and ...' logic as if whatever one chooses does not matter because the contradictoriness of the situation is supposed to have been overcome by a priori rejection of contradiction as a category. However, this move can hardly obscure the fact that, especially in the case of 'the book,' and also in similar cases, although the logic of 'and' is employed for not choosing between two terms, one of them is being continuously privileged over the other. ${ }^{8}$ Isn't it obvious that Deleuze and Guattari would much prefer "A book is not an image of the world" over its opposite? Now if a radical critique of binarism is an attempt at giving an explanation of not only how in metaphysical tradition thought is structured on oppositions, but also, how one is privileged over the other, then the appropriation of binarism into rhizome, without doubt,

${ }^{8}$ Another fine example of how privileging functions despite its rejection by Deleuze can be found in the following paragraph where Deleuze is discussing the world of simulacra: "It is not even enough to invoke a model of the Other, for no model can resist the vertigo of the simulacrum. There is no longer any privileged point of view except that of the object common to all points of view. There is no possible hierarchy, no second, no third.... Resemblance subsists, but it is produced as the external effect of the simulacrum, inasmuch as it is built upon divergent series and makes them resonate" $(2003,262)$. Isn't simulacrum privileged here over the world of models and copies, or mimesis? 
gets away from oppositions as such, but at the cost of still privileging, for example, mapping over decalcomania, or "A book is not the image of the world," over "A book is the image of the world."

I believe this type of contradiction, which is embodied in the text as 'privileging,' is also what opens up the situation to the question of the undecidable. If the undecidable is not simply a case where the possibility of reaching a decision is problematised, but also any ground for privileging one term over the other disappears, then in Deleuze's case a certain decision, despite its undecidability, is already made before the alterations between "and ... and . . and ..." logic starts. In other words, although the preservation of the opposites in the rhizome cannot be explained by referring to categorical contradiction in Deleuze and Guattari, the privileging of one term over the other can be, because even the elimination of mimesis cannot be achieved without referring to mimesis. Furthermore, such privileging points to an already-given decision about one term in the binaries, and also a more general decision about mimesis (the project of eliminating mimicry from thought). And isn't such privileging also related to the question of resonance which fails to eliminate the question of the first?

\title{
Two: On Exactitude in Science
}

\begin{abstract}
... In that Empire, the Art of Cartography attained such Perfection that the map of a single Province occupied the entirety of a City, and the map of the Empire, the entirety of a Province. In time, those Unconscionable Maps no longer satisfied, and the Cartographers Guilds struck a Map of the Empire whose size was that of the Empire, and which coincided point for point with it. The following Generations, who were not so fond of the Study of Cartography as their Forebears had been, saw that that vast Map was Useless, and not without some Pitilessness was it, that they delivered it up to the Inclemencies of Sun and Winters. In the Deserts of the West, still today, there are Tattered Ruins of that Map, inhabited by Animals and Beggars; in all the Land there is no other Relic of the Disciplines of Geography. ${ }^{9}$
\end{abstract}

-J. L. Borges

\section{Three}

I quoted this "fiction" from Borges because of its relevance for a discussion on the distinction between decalcomania and mapping. First of all, a brief etymological exploration of the word, decalcomania, will clarify its relation to tracing.

${ }^{9}$ Borges (1998). 
DECALCOMANIA: French décalcomanie, from décalquer to copy by tracing (from dé- de- + calquer to trace, from Italian calcare, literally, to tread, from $\mathrm{L}$ ) + manie mania, from Late Latin mania.

Date: 1864

$1:$ the art or process of transferring pictures and designs from specially prepared paper (as to glass)

2: DECAL Etymology: short for decalcomania

Date: 1937

: a picture, design, or label made to be transferred (as to glass) from specially prepared paper.

3. CAULK: Etymology: Middle English caulken, from Old

North French cauquer to trample, from Latin calcare, from calc-, calx heel

Date: 15 th century

: to stop up and make tight against leakage (as a boat or its seams, the cracks in a window frame, or the joints of a pipe). ${ }^{10}$

Decalcomania is a word for tracing a figure especially when it is considered within the context of a mania in the 19th century France, and Europe in general. First of all, it requires a figure to be copied on a piece of specially prepared paper by tracing, just as the Cartographers of the Empire in Borges' fiction would trace every detail in their activity of mapping. Once copied on a piece of paper, the figure is then ready to be transferred onto another surface in a similar fashion to that of stamping. Although there is seemingly a parallelism between the activity of the cartographers and decalcomania, "every detail" in Borges' fiction, though the writer talks about such an exactitude between the map and topography, is only an exaggeration that points to an impossibility in any type of map-making. No matter how exact one would like to be in map-making, unlike in an activity of decalcomania, there will always remain some points which escape such an act of copying, and therefore a full figure will never come about.

All this reminds us the difference that Deleuze and Guattari introduce between decalcomania and mapping: if mapping is privileged over decalcomania it is because tracing in the sense of decalcomania always requires a definite figure to be copied and transferred on to another surface, whereas mapping is that activity which opens up this process to an infinity: it is an act of copying where an exactitude is required but the fullness of a figure will never be attained.

10See http://www.m-w.com/cgi-bin/dictionary. 
However, as the etymology bears witness to, despite this contrast between the two words with respect to the emergence of a figure, what underlies both activities is tracing in the sense of the French word, décalquer. Both of them require a certain degree of resemblance, an exactitude between the model and its copy, yet if in decalcomania, the emergence of a figure is necessarily to be maintained, in mapping, though a point-to-point exactitude is required, a figure as a whole will never emerge.

Now I would like to point to the dictionary entry number 3 above and discuss a bit more about the resemblance between decalcomania and mapping with respect to décalquer (to copy by tracing). Décalcomanie is not only derived from décalquer but it is also related to "caulk," the Middle English caulken, which is derived from Old North French cauquer (to trample), which is in turn derived from "Latin calcare, from calc- calx, heel." Thought within this complexity of signifiers "caulk" means "to stop up and make tight against leakage (as a boat or its seams, the cracks in a window frame, or the joints of a pipe)." Then, if the underlying element (though not etymologically for cartography means: "the art or technique of making maps or charts. French cartographie : carte, map (from Old French, from Latin charta, carta, paper made from papyrus) + (-graphie, writing [from Greek graphia] $)^{11}$ of both décalcomanie and mapping is décalquer, the latter in its relation to caulk is what complicates the activity inherent to "caulk." In other words, if "to caulk" is a verb used to delimit that which escapes the limits, or to describe a shield against an attack from outside, décalquer is that verb which preserves the act of copying by faintly referring to these limits. Once again thought with respect to its Latin sources, "to caulk" is also related to "heel" which might be taken as one of the primal ways of stamping the earth, or leaving a trace. The trace of a foot (animal, human, or etc.), a signature, indeed. A kind of "Killroy was here," yet due to the organicity of which can never be held responsible for producing an exact resemblance to something, except in the form of "a human foot, a woman's foot, a wolf's feet etc.," always in an indefinite form.

From such an etymology, it can be seen that the distinction between decalcomania and mapping is a flexible one for both of them are traced back to a complexity of words for which any kind of decision about an exactitude of resemblance between model and copy is a problematical issue. Here, I should make it clear, my intention is not to be critical of Deleuze and Guattari because the distinction they produce between decalcomania and mapping is not a very rigid one, but because such a distinction hides some unquestioned realms in their theory, such as, some presumed relationships between a model and a copy, which the

${ }^{11}$ See http://www.bartleby.com/61/34/C0133400.html. 
theory aims to keep in check, yet which, as the etymology bears witness to, escape such checks. A question of the undecidable, especially when 'mimesis' is concerned.

\section{Four}

In the 'Appendix I' of The Logic of Sense, Deleuze introduces his own thought on simulacra by way of going through Plato's discussion on models and copies. If Plato rejects simulacra, it is because it is "an image without resemblance" whereas the relationship between a model and a copy should be based on an internal resemblance. The resemblance between model and copy is an internal affair so that the degree of resemblance between the two can be checked or validated, whereas the relationship between model and simulacrum is not based on such a resemblance (it is "an external effect"): "the simulacrum is not simply a false copy, but that it places in question the very notations of model and copy" (256). If simulacrum is that which puts in question the necessity of models and copies, then it is also what puts at stake the question of essence and appearance, necessity and redundancy, etc. In other words, the concept of simulacrum in Deleuze functions as a means of positing an endless, infinite chain of references and, an infinite deferral of reference in the absence of models which, transcending the question of transcendence, builds up a field of immanence.

So "to reverse Platonism" means to make the simulacra rise and affirm their rights among icons and copies. The problem no longer has to do with the distinction Essence-Appearance or Model-Copy. This distinction operates completely within the world of representation.... The simulacrum is not a degraded copy. It harbors a positive power which denies the original and the copy, the model and the reproduction. At least two divergent series are internalised in the simulacrum-neither can be assigned as the original, neither as the copy .... There is no possible hierarchy, no second, no third .... Simulation is the phantasm itself, that is, the effect of the functioning of the simulacrum as machinery - a Dionysian machine. (262-63)

I quoted this passage from Deleuze not only because it aims to summarize and brings to a finality the Deleuzian project of constructing a totally new way of dealing with representation but also because it ends up with a strange formulation of all the theory: "a Dionysian machine" - which I will dwell on in the next section.

Let us assume for the moment that in this and similar paragraphs, Deleuze, by privileging simulacra over mimesis, asserts that 
simulacrum is a means of getting rid of the determinations of the original and the copy, the model and the reproduction, Making this assumption, I would like to focus now on two examples given by Deleuze when he is explaining actualisation and counter-actualisation with respect to a complex cause-effect relationship.

The first example is related to a Stoic sage waiting for the event. The sage, as Deleuze puts it, "identifies with the quasi-cause," and "wills the embodiment and the actualisation of the pure incorporeal event in a state of affairs and in his or her own body and flesh" (146). Furthermore; a) "all bodies are causes in relation to each other, and causes for each other" (4); b) bodies are causes of the effects which are not bodies, but incorporeal entities: events. "Incorporeal effects are never themselves causes in relation to each other; rather, they are only "quasi-causes" following laws which perhaps express in each case the relative unity or mixture of bodies on which they depend for their real causes" (6).

Thus, "Identifying with the quasi-cause, the sage wishes to "give a body" to the incorporeal effect, since the effect inherits the cause" (147). Deleuze explains the necessity of "quasi-cause," by referring to an example by Goldschmidt. "The walk, incorporeal insofar as it is a way of being, acquires a body" (147). Now, all this discussion on the "quasicause," of course, emanates from a concern to change the hierarchical order between cause and effect. As Deleuze puts it: "[Stoics] are in the process of bringing about, first, an entirely new cleavage of the causal relation. They dismember this relation, even at the risk of recreating a unity on each side" (6).

It all means that one cannot think of a walk as independent from a body that will actualise it: though a body is the cause of the walk, the body cannot walk without the walk being the quasi-cause of the body's walk. The walk is an incorporeal effect; it cannot come before the body, its cause is the body but the body cannot walk without this incorporeal effect being the quasi-cause of its walk. My body does not imitate the idea of walk, and when I walk I do not imitate the event, the walk. Rather, the relationship between the two is simulacral, based on a "disjunctive synthesis."

However, even in this formulation, one still wonders whether the body is not that which acts as the primary cause whereas the quasi-cause (the almost, the virtual cause) is the secondary one? Deleuze does not neglect this problem: he asks: "But how could the sage be the quasicause of the incorporeal event, and thereby will its embodiment, if the event were not already in the process of being produced by and in the depth of corporeal causes . . . ?" (147). Although this 'answer-question' sounds complex, it means: If the sage becomes the quasi-cause of the incorporeal event by willing its embodiment, it is because the event is already in the process of being produced by and in the depth of 
corporeal causes. Hence, the double causality of the situation. With this answer, Deleuze preserves the cause and effect duality and he also resolves the problem of a hierarchical order between the two. Therefore, we should stop asking which comes first.

Yet, on the level of representation, the actor, actualisation and counter-actualisation things slightly differ and this brings us to the second example ("Twentieth" and the "Twenty-first Series" of The Logic of Sense). According to the Stoic conception of bodies and events, what an actor represents is that role which has been and which will be but never is. The actor is only as a body and the representation is always what has been and what will be. "The actor occupies the instant, while the character portrayed hopes or fears in the future and remembers or repents in the past: it is in this sense that the actor represents. . . To limit the actualisation of the event in a present without mixture, to make the instant all the more intense, taut and instantaneous since it expresses an unlimited future and an unlimited past. This is the use of representation: the mime and no longer the fortune-teller" (147). In other words, here representation occurs but just in the form of giving the lie to representation. In such a framework, one cannot talk about an actor playing a pre-determined role for the role as such is eliminated by the same move of representing just for the sake of giving the lie to representation. And, hence, the reference to the mime whose performance is not based on a model-copy relationship. If the mime is the one for whom there is no visible role depicted as such preceding the performance, what we observe as a performance is only a simultaneous relationship between actualising and counter-actualising forces.

I am thinking of watching the performance of a mime who is using his body and gestures in such a way so that I understand that he is drinking from a glass. Does not that mean we understand it because what he is copying is a man-drinking-from a glass?

Five

Firstly, because thought cannot stop itself from interpreting immanence as immanent to something, the great Object of contemplation, the Subject of reflection, or the Other subject of communication: then the transcendence is inevitably introduced.

-Gilles Deleuze and Felix Guattari ${ }^{12}$

${ }^{12}$ Deleuze and Guattari $(1994,51)$. 
Why Dionysian machine? What might have been Deleuze's intention when, at the end of the paragraph above, he evoked the name of Dionysos?

Any attempt at answering this question calls for an analysis of 'the immediate' (theorisation of which first takes place in Difference and Repetition through a critique of mediation on the ground that mediation cannot understand difference and repetition without representing them in 'concepts') in Deleuze's theorisation of simulacra, and also its relation to the obscure relationships that Nietzsche (1967) developed between Dionysos and Apollo for which he had the following reservations and distinctions:

Thus far we have considered the Apollonian and its opposite, the Dionysian, as artistic energies which burst forth from nature herself, without the mediation of the human artist (ohne Vermittelung des menschichen Künstlers)-energies in which nature's art impulses are satisfied in the most immediate and direct way-first in the image world of dreams, whose completeness is not dependent upon the intellectual attitude or the artistic culture of any single being; and then as intoxicated reality, which likewise does not heed the single unit, but even seeks to destroy the individual and redeem him by a mystic feeling of oneness. With reference to these immediate art-states of nature, every artist is an "imitator," ("Nachahmer") that is to say, either an Apollonian artist in dreams, or a Dionysian artist in ecstasies, or finally-as for example in Greek tragedy - at once artist in both dreams and ecstasies; so we may perhaps picture him sinking down in his Dionysian intoxication and mystical self-abnegation, alone and apart from the singing revelers, and we may imagine how, through Apollonian dream inspiration, his own state, i.e., his oneness with the inmost ground of the world, is revealed to him in a symbolical dream image. (38)

What is obviously discernible in this passage ${ }^{13}$ is that for Nietzsche there are two levels in the production of a work of art. The first level takes place within a dream-like world where images are formed just to be destroyed the next moment, and there, Nietzsche does not talk about an artist, for this is what happens before an absolute separation from nature, and, with respect to the creation of such images and their destruction, everyone is an artist without knowing it: here it is the immediate that which rules. The artist, on the other hand-but not in opposition to this first level-is he who, operating on the second level, imitates this process with an end product of a work of art. The two

${ }^{13}$ For a detailed discussion on the question of 'the immediate' in Schopenhauer and Nietzsche, see my forthcoming article, "Noise on Noise." 
levels are thus separated from each other with the production of an artwork, which must point to the endless transformation of the Apollonian into Dionysian, and vice versa. In other words, what happens on the first level acts as a model on which the artistic production on the second level comes as a copy. If what happens on the first level happens without the mediation of an artist, that is, immediacy is what determines the Dionysian world, on the second level, the artist, due to his function as a mediator, stands as an obstacle in front of this immediacy. However, this formulation can never be taken as the production of artwork as an aesthetic object because, given Nietzsche's notion of 'the tragic,' an artwork, while copying the first realm (the immediate as the model) can never produce an absolute distance from the 'noise' of the first realm. ${ }^{14}$

If one should think about the two levels for the production of the artwork which Nietzsche introduced when he was dealing with the question of the immediate in The Birth of Tragedy, what Deleuze offers as Dionysian machine in the paragraph above should be understood as an absolute regression into the infinite transformations of dreams into images and vice versa where a separation from nature has not yet taken place. When Nietzsche reserves the production of the artwork to the second level, due to the impossibility of theorising the immediate as such, it was probably because of a contradiction which he was afraid of: the realm of the immediate where man has not been separated from nature could not be theorised unless one a priorily assumed that this separation has already taken place. In other words, if Nietzsche were to insist on the first level, it was obvious that the artwork would remain as a residue in the realm defined as immediate. In contrast, for him, given the impossibility of theorising the immediate outside a system of signification, the best thing that an artwork could do would be to point to the realm of the immediate, though not without short-circuiting the system of signification, that is, without yielding to 'noise. ${ }^{\prime 15}$

Now if we go back to our initial question,"Why Dionysian machine?," it will be seen that this question not only throws light to a claim, Deleuze's claim to theorise the immediate (which Nietzsche shunned from) through a privileging of simulacra, but it also gives way to further questions about the place of the artwork in Deleuze. For example, if through the plane of immanence what is also theorised is the immediate, then why should there still be a need for the work, or rather, would not the artwork remain as a residue in this plane?

Without doubt, a possible answer to this question should be sought for in Deleuze and Guattari's thought on the plane of immanence where

${ }^{14}$ Nietzsche explains this point by referring to the position of the lyrist, the tragedian and the art of music. See Nietzsche (1967), sections, 2, 5 and 6.

${ }^{15} \mathrm{~A}$ detailed account of the centrality of 'noise' in Nietzsche's philosophy can be found in my "Noise on Noise." 
immanence is taken as immanent not to something else but only to itself. It is only this way, as they argued in What is Philosophy? (1994), the return of the transcendental, or of 'the first' is obstructed. ${ }^{16}$ And when they think about the artwork, they do so in such a system of immanence, and the main question here is without doubt whether an artwork can still be thought as something which represents something else. And if they think that it can be thought as representing nothing it is because simulacrum is that which governs the plane of immanence. Artworks do not represent anything for there is no such a model-copy relationship in a field of immanence.

Such reasoning unavoidably yields to several questions about artist and artwork which Nietzsche paid attention to in The Birth of Tragedy: First of all, if artworks do not represent anything, then, they should be thought as self-generative beings, capable of making themselves come into being. Second, if there is still the artwork, available to us as an object, then what happens to the immediacy of the plane? And, third, does the destruction of models and copies destroy also the act of copying, or isn't it rather that copying is that which, remaining intact, enables simulacra function-though within the absence of a definite model and a definite copy?

Is it once again a question of a transcendental forcing its way back to the plane of immanence? Or is it a question of the persistence of the act of copying? A question of decalcomania, mapping, and mimesis? A question of the first? A question of resonance?

\section{Six}

The conditions of a true critique and a true creation are the same: the destruction of an image of thought which presupposes itself and the genesis of the act of thinking in thought itself.

-Gilles Deleuze ${ }^{17}$

In Difference and Repetition, which is basically a rigorous critique of mimesis, the mediated, and representation, there is a curious, and fundamental chapter, "The Image of Thought" where Deleuze attempts at producing a critique of a certain ground, a system, out of which a philosophy can start. If the initial question of philosophy has always

16a)In What is Philosophy (1994) Deleuze and Guattari write: "Transcendence enters as soon as movement of the infinite is stopped. It takes advantage of the interruption to reemerge, revive, and spring forth again" (47).

b)In his "Immanence: A Life" essay (2001), Deleuze argues for a position of a transcendent which is not a transcendental but a necessity for the construction of a plane of immanence.

17Deleuze (2001a, 139). 
been the problem of where to start, the philosophers, as Deleuze discusses, found most of the time a way out by answering this question on the presupposition of a common sense. The common sense, as a genesis, a starting point of thought, had inevitably to invite a certain degree of morality into philosophy due to its presupposition: "everybody knows." For Deleuze, the image of thought cannot be but moralistic for its basic claim, or supposition is to bring an order, a system, to what is not thought: "recognition" is - as it follows from its founding principle, "everybody knows" - therefore the key word in any image of thought.

All this defines Deleuze's programme as follows:

As a result, the conditions of a philosophy which would be without any kind of presuppositions appear all the more clearly: instead of being supported by the moral Image of thought, it would take as its point of departure a radical critique of this image and the 'postulates' it implies. It would find its difference or its true beginning, not in an agreement with the pre-philosophical Image but in a rigorous struggle against this Image, which it would denounce as nonphilosophical. (2001a, 139)

As Heidegger did once, here Deleuze's attempt-as he quotes Heidegger a couple of pages later: "Man can think in the sense that he possesses the possibility to do so. This possibility alone, however, is no guarantee to us that we are capable of thinking" - is to be able to think of the unthought yet, of course, without any presuppositions (144). ${ }^{18}$ We will return to this question of presupposition later.

What Deleuze offers as an alternative to this image of thought, determined thoroughly by recognition, common sense and morals, is an "encounter," - that is an encounter between us and something which forces us to think ${ }^{19}$ - the primary characteristic of which is "sense," or its capacity to be sensed. In other words, sense, for Deleuze is that which comes before any act of recognition. What happens at the level of sense? Is it possible to theorise this level without turning it into a realm of recognition? Such an attempt, as the whole of Difference and Repetition, and later, The Logic of Sense bear witness to, requires a theorisation of the immediate, the sense and the event: a philosophy

${ }^{18}$ In the footnote for this quotation that he makes from Heidegger, Deleuze without doubt defines his position as follows: "It is true that Heidegger retains the theme of a desire or a philia, of an analogy - or rather, a homology - between thought and that which is to be thought. The point is that he retains the primacy of the Same, even if this is supposed to include and comprehend difference as such - whence the metaphors of gift which are substituted for those of violence. In all these senses, Heidegger does not abandon what we called above subjective presuppositions" (Difference and Repetition, 321).

${ }^{19}$ This sentence appears in the original as follows: "Something in the world forces us to think" (2001a, 139). 
which neither comes before nor after the event, but is produced at the moment of the taking-place of the event. I will not go into details of Deleuze's theory of the logic of sense in this essay, for it requires a scrutinisation of a vast area of thought with respect to questions of expression, denotation, signification, etc. Therefore, it will suffice to mention here in passing that what Deleuze continues in The Logic of Sense is the same project of theorising the immediate in Difference and Repetition, this time, within the framework of a rigorous theory of the event.

Deleuze's answer as to the possibility of a theorisation of the immediate, the guiding characteristic of which is sense, proceeds-at least in Difference and Repetition - first by way of defining 'sense' as a function of an 'intensity' that arouses in any encounter between us and something which forces us to think. In contrast to philosophies of recognition, 'pure difference' produced in such an encounter is the locus of sense yet, such a difference is also what is non-localizable in the sense of a possibility of playing the role of an origin. To reconstruct the situation by borrowing a term from Deleuze's own terminology, widely used especially in The Logic of Sense, what happens in such an encounter between us and something forces us to think, could probably be understood by referring to a certain concept of 'resonance. ${ }^{20}$ This would be another way of saying that in any act of thinking, it is not what we encounter, as a cause, which forces us to think, but sense, coming into life through resonance in the encounter between us and what forces us to think is what forces us to think. Bearing in mind the aim of destroying the image of thought, and also, the project of philosophy without presuppositions, let us proceed slowly at this point and listen to Deleuze (2001a) once again:

It is true that on the path which leads to that which is to be
thought, all begins with sensibility. Between the intensive and
thought, it is always by means of an intensity that thought
comes to us. The privilege of sensibility as origin appears in
the fact that, in an encounter, what forces sensation and that
which can only be sensed are one and the same thing, whereas
in other cases the two instances are distinct. (144-45)

Yes, here any hiearachy between "what forces sensation" (in a subject?) and "that which can only be sensed," (an object?) is destroyed for a philosophy without presuppositions, a philosophy with no image of thought, for a philosophy of the immediate. However, at the cost of following questions:

${ }^{20}$ For an elaboration of the thought on "resonance" in Heidegger, Agamben, Nietzsche and Derrida, see my "On Rhythm, Resonance and Distortion." 
What happens to difference if "what forces sensation and that which can only be sensed are one and the same thing" in an encounter? Simply put, if there is no difference between "what forces sensation and that which can only be sensed," how will it be possible for difference to give birth to "sense"? Can this be a move to eliminate what insistently comes back as an unresolved question of mimesis, representation, models and copies? Is it a concern for eliminating the primary position of "what forces sensation"? A concern for eliminating the hierarchy that keeps coming back to the theory? Does Deleuze take these steps in order to get away from the question of 'the first'?

Here, something else also happens: not only the presumed form of resonance is destroyed-one cannot talk about resonance at such a point which requires in the first place at least two distinct entities-but also it is revealed that the presumed type of resonance has not been functioning as presumed. If Deleuze had formerly rejected the image of thought, based on a presupposition, and the primacy of this presupposition in starting any activity of thought, it was supposedly because the model on which it operated required a hierarchy where a primary source started all the movement of vibration so that a second entity (a thought) would get into resonance with it. Deleuze's intention of destroying the image of thought in that sense called for a different type of resonance where two separate entites would always already be in resonance without the necessity of one of them being the initiator of resonance.

However, what happens within the context of the passage above cannot be considered as the second type of resonance: for it is obvious that it is simply preferred by Deleuze at the moment of a crisis in theory. Can one correct it by claiming that they are the same-for there should be no hierarchy between the two-when one understands that what has been posited as the emergence of sense (as that which happens between "what forces sensation" [in a subject?] and "that which can only be sensed" [an object?]) is but the reappropriation of what has been criticized as the "image of thought"? And, at the cost of destroying the schema of difference as the non-originary origin of sensation?

The nature of that which insistently comes back to the plane of immanence is made more explicit ${ }^{21}$ in one of the interviews where Deleuze (1995) talks about rhizome, the image of thought, and concepts:

...then I come to it again, with Félix, in A Thousand Plateaus, because the rhizome's the image of thought that spreads out

${ }^{21}$ For another example of the upsurging question of mimesis, see especially, Deleuze and Guattari (1994): "The plane of immanence is like a section of chaos and acts like a sieve" (42), and "The philosophical sieve, as plane of immanence that cuts through the chaos ..." (118). Isn't then the plane of immanence, though rhizomic, that which is able to give form to chaos? 
beneath the tree image. We've got no model for dealing with this question, no guide even...

This is all I'm saying: there's a hidden image of thought that, as it unfolds, branches out, and mutates, inspires a need to keep on creating new concepts, not through any external determinism but through a becoming that carries the problems themselves along with it. (149)

Does Deleuze talk about only that there is no model here which the concepts copy, or that there is no such mechanism of model and copy between image of thought (rhizome) and concepts? That is, no act of copying?

If there is no model, then does it mean that the act of copying also disappear? In fact, what Deleuze is stressing here is a model which opens itself to infinity and, hence, something which is a model without being a model. In such a framework, the act of copying without doubt does not disappear: on the contrary, what we are left with is only the act of copying, yet without a definite model. An indefinite copy with respect to an indefinite model.

However, then this issue gives way to some problematic positions such as formerly maintained thoughts on immanence. If immanence is where the problem of transcendence is resolved by positing a transcendent which is not transcendental, ${ }^{22}$ a transcendent which deos not and cannot transcend the plane of immanence, that which is maintained as a residue, the act of copying, which still works on the relation of model and copy (it does not matter here whether they are definite or indefinite), is what introduces into the thought on immanence the question of 'the first.' Can the consideration of model and copy as indefinite concepts save the model from functioning as a transcendental ? Isn't this relationship what transcends the plane of immanence?

Can copy constitute its model at the moment of its copying a model? Even so, such a modelling of the relationship between model and copy will give life to a transcendent which is transcendental, and thus which escapes from the plane of immanence to an outside. This strife, the strife of transcending metaphysics is without doubt, a Nietzschean project, the most spectacular embodiment of which is in Thus Spoke Zarathustra to which Derrida referred to in "The Ends of Man":

We know how, at the end of Zarathustra, at the moment of the "sign," when das Zeichen kommt, Nietzsche distinguishes, in the greatest proximity, in a strange resemblance and an ultimate complicity, at the eve of the last separation, of the

22See especially, Deleuze (2001b). 
great Noontime, between the superior man (höhere Mensch) and the superman (Übermensch). The first is abandoned to his distress in a last movement of pity. The latter-who is not the last man - awakens and leaves, without turning back to what he leaves behind him. His laughter then will burst out, directed toward a return which no longer will have the form of the metaphysical repetiton of humanism, nor, doubtless, "beyond" metaphysics, the form of a memorial or a guarding of the meaning of Being, the form of the house and of the truth of Being. He will dance, outside the house, the aktive Vergesslichkeit, the "active forgetting" and the cruel (grausam) feast of which the Genealogy of Morals speaks. No doubt that Nietzsche called for an active forgetting of Being: it would not have the metaphysical form imputed to it by Heidegger.

Must one read Nietzsche, with Heidegger, as the last of the great metaphysicians? Or, on the contrary, are we to take the question of the truth of Being as the last sleeping shudder of the superior man? Are we to understand the eve as the guard mounted around the house or as awakening to the day that is coming, at whose eve we are? Is there an economy of the eve?

Perhaps we are between these two eves, which are also two ends of man. ${ }^{23}$ But who, we? ${ }^{24}$

BILKENT UNIVERSITY, TURKEY

\section{References}

Aracagök, Zafer. "On Rhythm, Resonance and Distortion." Pli: The Warwick Journal of Philosophy 14 (2003).

"Noise on Noise." SubStance. Forthcoming.

Borges, Jorge Luis. Collected Fictions. Trans. Andrew Hurley. New York: Viking Penguin, 1998.

Deleuze, Gilles. The Fold: Leibniz and The Baroque. Trans. Tom Conley. Minneapolis: U of Minnesota P, 1993.

. “On Philosophy." Negotiations. Trans. Martin Joughin. New York: Columbia U P, 1995. 149.

- Difference and Repetition. Trans. Paul Patton. London: Continuum, 2001a.

"Immanence: A Life." Pure Immanence: Essays on A Life. Trans. Anne Boyle. New York: Zone Books, 2001b.

The Logic of Sense. Ed. Constantin Boundas. Trans. Mark Lester with Charles Stivale. London: Continuum, 2003.

\footnotetext{
${ }^{23}$ Derrida $(1992,135-36)$.

${ }^{24} \mathrm{~A}$ different version of this article was presented at "Conference: Gilles Deleuze: Experimenting with Intensities," 12-15 May 2004, Trent University, Peterborough, Canada.
} 
"On Gilbert Simondon." Desert Islands and Other Texts 1953-1974. Ed. David Lapoujade. Trans. Michael Taormina. NY: Semiotexte, 2004. and Felix Guattari. What is Philosophy?. Trans. Hugh Tomlinson and Graham Burchill. London: Verso, 1994.

and Felix Guattari. A Thousand Plateaus. Trans. Brian Massumi. Minneapolis: U of Minnesota P, 1987.

Derrida, Jacques. "The Ends of Man." Margins of Philosophy. Trans. Alan Bass. Chicago: U of Chicago P, 1992.

Nietzsche, Friedrich. The Birth of Tragedy. Trans. W. Kaufmann. New York: Vintage Books, 1967.

Plotnitsky, Arkady. Complementarity: Anti-Epistemology After Bohr and Derrida. Durham: Duke U P, 1994.

Plotnitsky, Arkady. The Knowable and the Unknowable: Modern Science, Nonclassical Thought, and the "Two Cultures." Ann-Arbor: U of Michigan P, 2002.

"Resonance." The Oxford English Dictionary. Online edition. 2005. $<$ http://dictionary.oed.com/>. 